\title{
Semen quality in patients with pituitary disease and adult-onset hypogonadotropic hypogonadism
}

\author{
Mikkel Andreassen ${ }^{1}$, Anders Juul ${ }^{2}$, Ulla Feldt-Rasmussen ${ }^{1}$ and Niels Jørgensen ${ }^{2}$ \\ 1Department of Endocrinology, Faculty of Health Science, Rigshospitalet, University of Copenhagen, Copenhagen, Denmark \\ 2Department of Growth and Reproduction, Faculty of Health Science, Rigshospitalet, University of Copenhagen, Copenhagen, Denmark \\ Correspondence should be addressed to M Andreassen: mikkel.andreassen.01@regionh.dk
}

\begin{abstract}
Objective: Gonadotropins (luteinizing hormone (LH) and follicle-stimulating hormone $(\mathrm{FSH}))$ are released from the pituitary gland and stimulate Leydig cells to produce testosterone and initiates spermatogenesis. Little is known about how and when the deterioration of semen quality occurs in patients with adult-onset gonadotropin insufficiency.

Design and methods: A retrospective study comprising 20 testosterone-deficient men (median age, 29 years) with acquired pituitary disease who delivered semen for cryopreservation before initiation of testosterone therapy. Semen variables and hormone concentrations were compared to those of young healthy men $(n=340)$. Results: Thirteen of 20 patients $(65 \%)$ and $82 \%$ of controls had total sperm counts above 39 million and progressive motile spermatozoa above $32 \%(P=0.05)$. For the individual semen variables, there were no significant differences in semen volume (median (intraquartile range) $3.0(1.3-6.8)$ vs $3.2(2.3-4.3) \mathrm{mL}, P=0.47)$, sperm concentration 41 $(11-71)$ vs $43(22-73) \mathrm{mill} / \mathrm{mL}(P=0.56)$ or total sperm counts $(P=0.66)$. One patient had azoospermia. Patients vs controls had lower serum testosterone 5.4 (2.2-7.6) vs 19.7 (15.5-24.5) $\mathrm{nmol} / \mathrm{L}(P=0.001)$, calculated free testosterone (cfT) 145 (56-183) vs 464 (359-574) pmol/L $(P<0.001)$, LH $1.5(1.1-2.1)$ vs $3.1(2.3-4.0) \mathrm{U} / \mathrm{L}(P=0.002)$ and inhibin b $(P<0.001)$. Levels of FSH were similar $(P=0.63)$. Testosterone/LH ratio and $\mathrm{CfT} / \mathrm{LH}$ ratio were reduced in patients (both $P<0.001$ ).

Conclusions: Despite Leydig cell insufficiency in patients with acquired pituitary insufficiency, the majority presented with normal semen quality based on the determination of the number of progressively motile spermatozoa. In addition, the data suggest reduced LH bioactivity in patients with pituitary insufficiency.
\end{abstract}

\author{
Key Words \\ - semen quality \\ - bioactivity of \\ gonadotropins \\ - hypogonadotropic \\ hypogonadism \\ - male reproduction
}

\section{Introduction}

The gonadotropins, luteinizing hormone (LH) and follicle-stimulating hormone (FSH) are released from the gonadotropic cells in the anterior pituitary gland. In men, the main target cells for LH are Leydig cells with subsequent testosterone secretion. FSH primarily stimulates Sertoli cells adjacent to germ cells within the seminiferous tubules. Intratesticular testosterone stimulated by LH, and stimulation of Sertoli cells by FSH seems both important for induction of spermatogenesis in humans, although some controversy exists $(1,2)$. Through negative feedback, testosterone is the predominant regulator of LH, whereas inhibin $b$ is the predominant regulator of
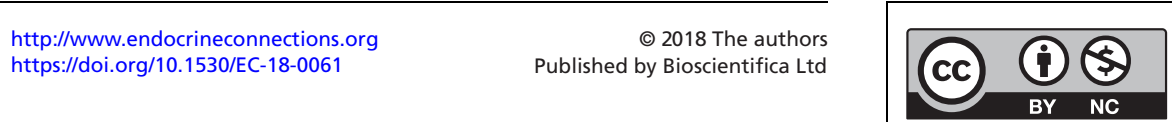

This work is licensed under a Creative Commons Attribution-NonCommercial 4.0 International License. 
FSH (2). Congenital hypogonadotropic hypogonadism $(\mathrm{CHH})$ is associated with an infantile phenotype with lack of testicular growth and absent testosterone and sperm production. In contrast to $\mathrm{CHH}$, normal testicular volume can be observed in patients with acquired adult-onset hypogonadotropic hypogonadism $(3,4)$.

The vast majority of patients with adult-onset pituitary insufficiency, independent of reason, have partial insufficiency with detectable but inappropriately low levels of pituitary hormones including gonadotropins (5), and the condition will usually result in testosterone deficiency at some point $(6,7)$. However, little is known about how and when deterioration of semen quality occurs in these patients. Previous studies have primarily examined semen quality in prolactinoma patients with reversible hypogonadism, and the effect of dopamine agonist treatment $(8,9,10,11,12)$. There are in vitro, as well as clinical data, suggesting that prolactin per se affects male reproductive tissue in addition to the wellknown suppressive effect on release of gonadotropins $(13,14,15)$. Therefore, results obtained in patients with hyperprolactinemia may not be extrapolated to patients with hypogonadotropic hypogonadism due to other diseases.

In the present study, we examined semen quality in a group of adult men with documented pituitary disease, at the time when secondary testosterone deficiency requiring testosterone treatment became apparent. The aim was to evaluate, if the two components of the gonadal axis, spermatogenesis and steroidogenesis, was influenced differently by pituitary insufficiency.

\section{Subjects and methods}

\section{Participants}

It was a single-center retrospective study comprising patients from Department of Endocrinology, Rigshospitalet University of Copenhagen. Patients with pituitary diseases were offered cryopreservation of semen for future fertility treatment before testosterone therapy was initiated, or in selected younger cases before pituitary surgery or radiation therapy. All patients who started testosterone therapy between 2002 and 2016 due to pituitary diseases were evaluated $(n=409)$. Forty-seven patients (11.5\%) desired cryopreservation of semen. A diagnosis of hypogonadotropic hypogonadism was based on at least two measurements of low testosterone (nonfasting) with inappropriately low levels of gonadotropins and symptoms of testosterone deficiency. This approach is in agreement with current guidelines and reflects that there is no consensus on strict criteria to make a diagnosis of hypogonadotropic hypogonadism (16). Exclusion criteria were previous or ongoing treatment with testosterone or gonadotropins, onset of testosterone deficiency before puberty and testicular disease including cryptorchidism. Twenty patients were included in the study and 27 were excluded due to: Treatment with gonadotropins $(n=5)$, treatment with testosterone $(n=11)$, normal plasma testosterone on the day of cryopreservation $(n=3)$, childhood-onset hypogonatropic hypogonadism $(n=3)$, bilateral cryptorchidism $(n=2)$, unable to ejaculate $(n=2)$ and lack of clinical data $(n=1)$.

Four of the included patients had fathered children (2-8 years from conception to cryopreservation of semen).

Data on patient diagnoses are given in Table 1.

The control subjects were part of an ongoing crosssectional study of young Danish men who were included in collaboration with the Danish military health board (17). In Denmark all young men, except those with chronic severe diseases, are required to attend a compulsory medical examination before they may be considered for military service. The overall study population was recruited from 1996 to 2010 and consisted of 4867 individuals (average participation rate 24\%) (17). The present study consisted of all participants from the year 2005 without a history of pituitary or testicular disease including cryptorchidism $(n=340)$.

Levels of reproductive hormones in patients were also compared to age-specific reference ranges.

\section{Physical examination}

On the day the first semen sample was delivered to the semen laboratory, patients and controls underwent a physical examination at the Department of Growth and Reproduction, including evaluation of gynecomastia and assessment of testicular size by a wooden orchidometer (Pharmacia and Upjohn, Denmark) and by ultrasonographic evaluation. Furthermore, blood samples were collected for measurement of reproductive hormones.

\section{Semen samples}

All semen samples were analyzed at Department of Growth and Reproduction at Rigshospitalet. Patients and controls had been instructed to abstain from ejaculation 
Table 1 Patients characteristics.

Primary diagnosis
Acromegaly
Prolactinoma
Mixed GH and prolactin secreting
adenoma
Empty sella
Non-secreting adenoma
Craniopharyngioma
Medulla blastoma
Hypophysitis
Hormone substitution
Thyroxine
Hydrocortisone
Growth hormone
Desmopressin
Other treatments
Somatostatin analogs
Dopamine agonists
Radiation therapy before cryopreservation
of semen
Pituitary surgery before cryopreservation
of semen
Time since initial diagnosis of pituitary
disease, months

Numbers

8

2

2

1

1

5

5

1

2

2

7

5 (range 1-108)

Diagnoses and substitution therapy in the 20 patients with secondary testosterone deficiency.

for at least $48 \mathrm{~h}$ before attendance at the clinic. The semen samples were obtained by masturbation into a clean tube at a room adjacent to the laboratory. Samples were maintained at $37^{\circ} \mathrm{C}$ during liquefaction analysis. Semen analyses were performed based on the WHO guidelines, 1992, with modifications as previously described (17). Semen volume was estimated through weighing of the collecting tubes. For the assessment of sperm motility phase contrast microscopy ( $\times 400$ magnification) was done on fresh semen samples. Samples were classified as either progressive motile (WHO motility classes $\mathrm{A}+\mathrm{B}$ ), nonprogressive motile (WHO C) or immotile (WHO D). Sperm concentration was assessed using a haemocytometer (Bürker-Türk) on semen samples diluted in a solution of $\mathrm{NaHCO}_{3}$, formaldehyde and distilled water. Total sperm count was calculated as semen volume $\times$ sperm concentration, and total number of progressively motile spermatozoa as total sperm count $\times$ percentage of progressively motile spermatozoa. Normal values for semen quality was based on the WHO 2010 guidelines (sperm counts above 39 million and progressive motile spermatozoa above 32\%) (18).

In controls, semen characteristics were based on a single semen sample, whereas in the patients, it was based on the average of available samples (median 2 (range 1-5)).

\section{Blood samples}

Blood samples were drawn from an antecubital vein in the non-fasting state. Measurements of all reproductive hormone levels in patients and controls as well as the agespecific reference ranges were done at the same laboratory at Department of Growth and Reproduction.

Serum levels of FSH, LH, sex hormone-binding globulin (SHBG), testosterone and estradiol were measured by time-resolved immunofluorometric assays (Delfia, PerkinElmer). Intra-assay and interassay CVs for FSH and LH were 3 and 5\%. Intra-assay and interassay CVs for both SHBG and testosterone were $<8$ and $<5 \%$. For estradiol intra-assay and interassay CVs were $<4$ and $8 \%$. Serum inhibin b was measured by a specific two-sided enzyme immunometric assay (Serotec, UK), intra-assay and interassay CVs 15 and 18\%. Free testosterone (cfT) was calculated assuming a fixed albumin value of $43.0 \mathrm{~g} / \mathrm{L}$ using the calculation suggested by Vermeulen et al. (19).

\section{Statistics}

Descriptive statistics were used to summarize the subject characteristics. Results are presented as median and interquartile range. Continuous variables were compared by $T$-test, whereas categorical data were compared by $\chi^{2}$-test. Associations between variables were performed by regression analyses, examined for interaction between explanatory variables. To approximate normal distribution of the residuals reproductive hormone concentrations and percentage of motile spermatozoa were natural logarithm (ln) transformed, and other semen variables were cubic root transformed.

The relationship in patients between totaltestosterone and cfT vs the corresponding $\mathrm{LH}$ and between inhibin $\mathrm{b}$ vs the corresponding FSH were compared to controls from the general population using two-dimensional bivariate reference charts (20). The bivariate reference curves (97.5 percentile) separate individuals with an abnormal LH-testosterone (or LH-cfT or FSH-inhibin b) combination from individuals with a normal combination.

The statistical analyses were performed by SPSS, version 22. Two-sided $P$ values $<0.05$ were considered significant.

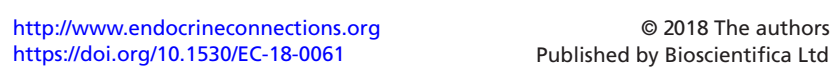




\section{Ethics}

The study was approved by The Danish Data Protection Agency (no:2012-58-0004) and conducted in accordance with the Helsinki Declaration. It was a retrospective study not requiring informed consent.

\section{Results}

Characteristics of the 20 patients are provided in Tables 1 and 2 . The 20 included patients were significantly younger than the patients who did not desire cryopreservation of semen $(n=362),(29$ (25-37) vs 53 (38-65) years, $P<0.001)$. Seven of the included patients had pituitary surgery before cryopreservation of semen. Patients with a history of acromegaly $(n=8)$, prolactinomas $(n=3)$ and mixed growth hormone and prolactin secreting adenomas $(n=2)$ comprised the largest groups of patients (Table 1). Five were treated with dopamine agonist and two with somatostatin analogs (Table 1). Five patients had slightly elevated s-prolactin (less than 5-times upper normal range). Among the ten patients diagnosed with acromegaly eight had elevated serum insulin-like growth factor 1 (IGF-I) concentrations (z-score between 4 and 12). Details on other hormone replacement therapies are given in Table 1.

The majority of the included patients started testosterone therapy soon after cryopreservation of semen. In three patients, testosterone treatment was postponed to preserve fertility.

Compared to healthy controls, patients were older and presented more frequently with gynecomastia (Table 2). Serum estradiol was lower in the patients, whereas

Table 2 Hormone levels and semen quality.

\begin{tabular}{|c|c|c|c|c|}
\hline & Patients $(n=20)$ & Controls $(n=340)$ & $P$ value & Z scores (patients) \\
\hline Age & $29(25-37)$ & $19 \pm 1$ & $<0.001$ & \\
\hline BMI (patients, $n=9$ ) & $26(21-30)$ & $22(20-24)$ & 0.14 & \\
\hline Abstinence (days) & $4(3-7)$ & $2(2-3)$ & 0.11 & \\
\hline Average testicular volume (orc) (mL) & $20(17-25)$ & $20(19-25)$ & 0.61 & \\
\hline Average testicular volume (US) (mL) & $14(10-18)$ & $14(11-17)$ & 0.62 & \\
\hline Gynecomastia (patients, $n=17$ ), numbers & $4 / 17$ & $5 / 340$ & $<0.001$ & \\
\hline \multicolumn{5}{|l|}{ Biochemical markers } \\
\hline Total testosterone (nmol/L) & $5.4(2.2-7.6)$ & $19.7(15.5-24.5)$ & $<0.001$ & $-2.5(-3.4$ to -1.8$)$ \\
\hline SHBG (nmol/L) & $17(10-34)$ & $26(20-34)$ & 0.03 & $-1.9(-2.2$ to 0$)$ \\
\hline $\begin{array}{l}\text { Calculated free testosterone }(\mathrm{cfT}) \\
(\mathrm{pmol} / \mathrm{L})\end{array}$ & 145 (56-183) & 464 (359-574) & $<0.001$ & $-2.0(-2.9$ to -1.6$)$ \\
\hline LH (U/L) & $1.5(1.1-2.1)$ & $3.1(2.3-4.0)$ & 0.002 & $-1.8(-2.0$ to -1.2$)$ \\
\hline FSH (U/L) & $2.4(1.4-4.5)$ & $2.2(1.5-3.3)$ & 0.63 & $-1.4(-2.0$ to 0.2$)$ \\
\hline Estradiol (pmol/L) & $40(20-70)$ & $60(50-80)$ & 0.001 & $-1.9(-2.2$ to 0$)$ \\
\hline Inhibin B (ng/L) & $142(129-184)$ & $227(176-285)$ & $<0.001$ & $-0.2(-0.5$ to 0.1$)$ \\
\hline Total testosterone/LH ratio & $3.2(1.5-4.8)$ & $6.5(4.6-8.7)$ & $<0.001$ & \\
\hline Calculated free testosterone/LH ratio & $77(37-118)$ & $152(111-206)$ & $<0.001$ & \\
\hline Inhibin b/FSH ratio & $63(35-116)$ & $105(57-171)$ & 0.01 & \\
\hline IGF-I ( $\mu \mathrm{g} / \mathrm{L})$ & $628(253-1161)$ & $279(233-328)$ & 0.03 & $4.5(0.2-10)$ \\
\hline Prolactin (U/L) & $250(128-478)$ & & & \\
\hline \multicolumn{5}{|l|}{ Semen characteristics } \\
\hline Semen volume $(\mathrm{mL})$ & $3.0(1.3-6.8)$ & $3.2(2.3-4.3)$ & 0.47 & \\
\hline Sperm concentration (mill./mL) & $41(11-71)$ & $43(22-73)$ & 0.56 & \\
\hline Total sperm counts (mill.) & $153(15-288)$ & $136(65-235)$ & 0.66 & \\
\hline Progressive motile (\%) & $49(13-63)$ & $57(47-67)$ & 0.04 & \\
\hline Progressive motile (mill.) & $77(17-177)$ & $82(34-140)$ & 0.51 & \\
\hline Non-progressive motile (\%) & $7(5-11)$ & $5(4-7)$ & 0.13 & \\
\hline Non-progressive motile (mill.) & $11(3-22)$ & $6(3-12)$ & 0.44 & \\
\hline Immotile (\%) & $41(32-67)$ & $37(27-46)$ & 0.14 & \\
\hline Immotile (mil) & $56(19-109)$ & $45(21-79)$ & 0.8 & \\
\hline
\end{tabular}

Comparisons between patients $(n=20)$ and controls $(n=340)$. Descriptive values are shown as medians and interquartile ranges. Hormone levels in patients are also compared to an age matched reference population and the results are expressed in standard deviation (s.D.) scores ( $z$-scores). *Normal semen quality was defined as total sperm counts above 39 million and progressive motile spermatozoa above $32 \%$.

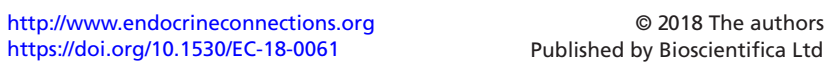

This work is licensed under a Creative Commons Attribution-NonCommercial 4.0 International License. 
estradiol/testosterone ratio was significantly higher in the patients compared to controls (Table 2). Testicular size was similar in patients and controls.

\section{Leydig cell function}

Time interval from 1st documentation of serum testosterone $<10 \mathrm{nmol} / \mathrm{L}$ to cryopreservation was in median 105 (IQR) 30-210 days. Median time interval from initial diagnosis of pituitary disease to cryopreservation was 5 months (range 1-108). On the day semen was cryopreserved, patients had lower serum levels of total testosterone $(P=0.001)$, SHBG $(P=0.03), \operatorname{cfT}(P<0.001)$, LH $(P=0.002)$ and estradiol $(P=0.001)$ compared to controls (Fig. 1 and Table 2). Hormone levels in patients, compared to age-specific reference ranges presented as SD scores (z-scores) are also given in Table 2 . The median $z$-score for testosterone and cfT were minus 2.5 and minus 1.95, respectively. Fifteen patients had serum total testosterone below the lower limit for age- and assay-specific reference range.

Total testosterone/LH ratio as well as cfT/LH ratio was significantly lower in patients compared to controls (Table 2). Adjusted for age and concentrations of LH serum testosterone and cfT were reduced by 12.4 (7.4-17.4) nmol/L and 283 (168-399) pmol/L, respectively in patients compared to controls (both $P<0.001$ ). There were no significant interactions between patients/ controls and LH in the two regression analyses. Serum LH was significantly associated to both total testosterone and cfT (both $P<0.001$ ), whereas age did not significantly influence testosterone or cfT (both $P=0.82$ ). The relationship between serum $\mathrm{LH}$ vs total testosterone and cfT in patients are presented in Fig. 2A and B using twodimensional bivariate plots. The patients are compared to a reference chart based on simultaneous measurements of $\mathrm{LH}$ and testosterone (2A) and LH and cfT (2B) $(n=706$, age $20-50$ years) (21). The curved lines in the two figures represent the 97.5 percentile reference curves. If the point is inside the curve, i.e. is in the upper left corner of the plot, the patient has a normal LH testosterone/ cfT combination. The patient is abnormal if the point is outside, i.e. to the right or below the curve. As seen in the two figures, the majority of patients had an abnormal LH testosterone combination and LH-cfT combination. When establishing the reference curves testosterone was measured by a radioimmunoassay (RIA) (21). Compared to the RIA, testosterone is on average measured $17 \%$ higher by the immunofluorometric assay used in the patients (data not shown). For LH and SHBG the same assays were used.

Levels of insulin-like growth factor 1 was significantly higher in the patients $(P=0.03)$.

\section{Spermatogenesis}

Data on semen quality are presented in Table 2. One of 20 patients had azoospermia compared to four of the 340 controls. For the patient with azoospermia data on semen volume was not available, and in another patient with very low semen volume $(0.2 \mathrm{~mL})$, data on sperm concentration were not determined.

Levels of inhibin b were reduced in patients $(P<0.001)$ compared to controls, whereas FSH $(P=0.62)$ did not differ. The inhibin $\mathrm{b} / \mathrm{FSH}$ ratio was also reduced in patients (Table 2). The FSH-inhibin b profile was also compared to a reference chart in a bivariate plot based on inhibin $b$ and FSH measurement (Fig. 3). Despite reduced inhibin b/ FSH ratio, all men had a normal FSH-inhibin combination when compared to men from the general population (full drawn line). Sixteen of 20 patients also had a normal combination when compared to proven fertile men, who had fathered children without use of assisted reproductive technologies (dotted line). The reference chart was based
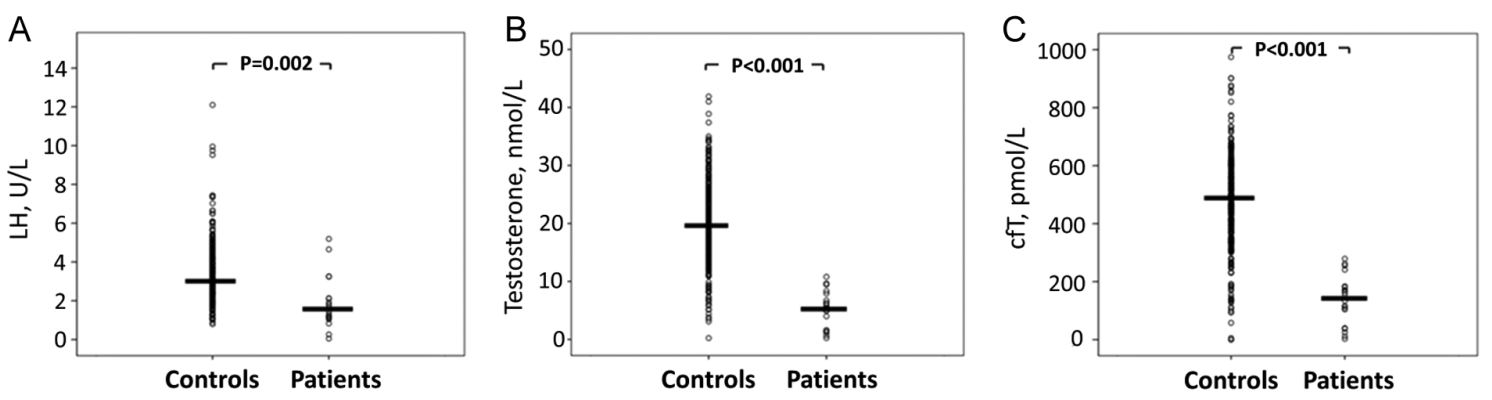

\section{Figure 1}

Levels of $\mathrm{LH}(\mathrm{A})$, testosterone (B) and calculated free testosterone (cfT) (C) in controls and patients. All individual measurements are presented in the figure. Horizontal lines represent the median.

$$
\begin{array}{lr}
\text { http://www.endocrineconnections.org } & \text { ○ } 2018 \text { The authors } \\
\text { https://doi.org/10.1530/EC-18-0061 } & \text { Published by Bioscientifica Ltd }
\end{array}
$$




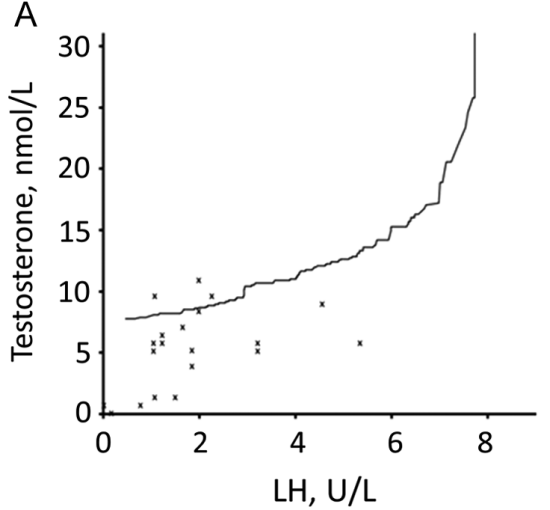

\begin{abstract}
Figure 2
LH vs total testosterone (A) and LH vs calculated free testosterone (cfT) (B) in men with acquired hypogonadotropic hypogonadism plotted in a bivariate reference chart. The curves represent the 97.5 percentile for men from the general population ( $n=706$, age $20-50$ years) (19). Points below the 97.5 percentile represent patients with an abnormal LH-testosterone (and LH-cfT) combination, and points above and to the left of both 97.5 percentiles represent individuals that have a normal combination.
\end{abstract}

on measurements in men aged 20-45 years, $n=307$ (general population) and $n=303$ (proven fertile men). The reference curves were established using the same assays for FSH and inhibin b as used in the patients (22).

There was a significantly lower percentage of progressively motile spermatozoa in patients compared to controls $49 \quad(13-63)$ vs $57 \quad(47-67) \% \quad(P=0.04)$. Thirteen patients (65\%) and $82 \%$ of controls had total sperm counts above 39 million and progressive motile spermatozoa above $32 \%(P=0.05)$, corresponding to the WHO 2010 reference levels for these variables (18). For the individual semen variables, there were no significant differences (patients vs controls) in semen volume $3.2(1.4-5.6)$ vs $3.2(2.3-4.3) \mathrm{mL}(P=0.47)$, sperm concentration 41 (11-71) vs $43(22-73) \mathrm{mill} / \mathrm{mL}(P=0.56)$ or total sperm counts $153(15-288)$ vs $136(65-235)$ mill $(P=0.66)$ (Fig. 4).

In univariate regression analyses, FSH was inversely associated with total sperm count, sperm concentration and inhibin $\mathrm{b}$ in the controls (all $P<0.001$ ). By contrast, no significant association between FSH and total sperm counts $(P=0.77)$, sperm concentration $(P=0.58)$ or inhibin b $(P=0.87)$ were observed in the patients.

In patients (univariate regression analyses), levels of testosterone were positively associated with semen volume $(P=0.01)$ and total sperm counts $(P=0.03)$ (Fig. 5), but not with the sperm concentration $(P=0.14)$. In the controls, no significant associations were found between testosterone vs semen volume $(P=0.1)$, total sperm counts $(P=0.20)$ or sperm concentration $(P=0.06)$.

A diagnosis of acromegaly or a diagnosis of prolactinoma was not significantly associated with total sperm count or sperm concentration. IGF-I, prolactin, duration of abstinence from latest ejaculation, time since initial diagnose of pituitary disease or duration of documented androgen deficiency also did not predict semen quality.

$$
\begin{aligned}
& \text { http://www.endocrineconnections.org } \\
& \text { https://doi.org/10.1530/EC-18-0061 }
\end{aligned}
$$

\section{Discussion}

We report that a large proportion of patients with adult-onset pituitary disease presented with normal semen quality at the time when testosterone deficiency became apparent. The only significant difference we could document was a lower percentage of progressively motile spermatozoa in patients compared to controls. Thus, despite severe and highly significant reduction of Leydig cell function with low total and calculated free

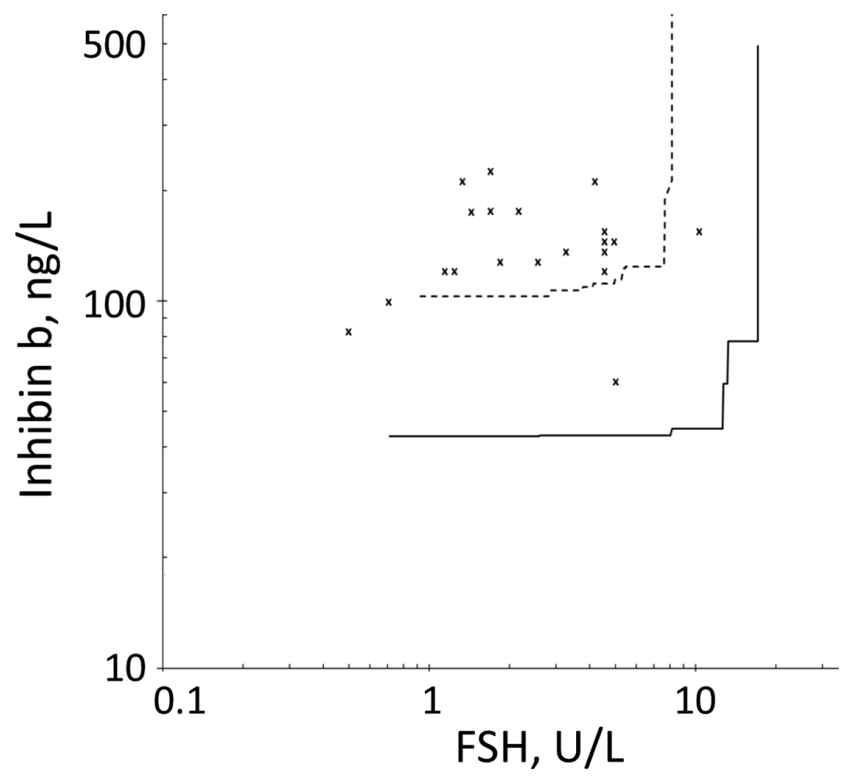

Figure 3

FSH vs inhibin $b$ in men with acquired hypogonadotropic hypogonadism plotted in a bivariate reference chart. The curves represent the 97.5 percentile for proven fertile men (dotted line, $n=303$, age 20-45 years) and the 97.5 percentile for men from the general population (full drawn line, $n=307$, age $20-45$ years) (20). Points above and to the left of both 97.5 percentiles represent patients that have a normal FSH-inhibin b combination. Points placed between the two 97.5 percentiles represent individuals who are identified as having normal hormone levels in relation to men from the general population but outside the normal range in relation to proven fertile men.

his work is licensed under a Creative Commons Attribution-NonCommercial 4.0 International License. 


\section{$B$}

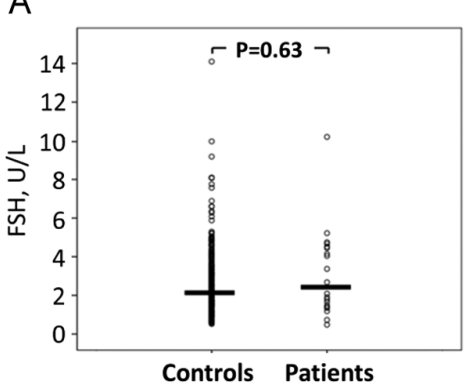

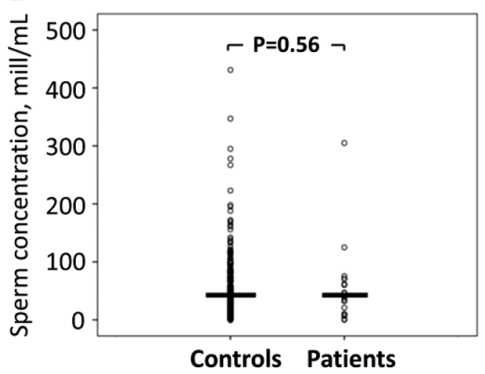

C

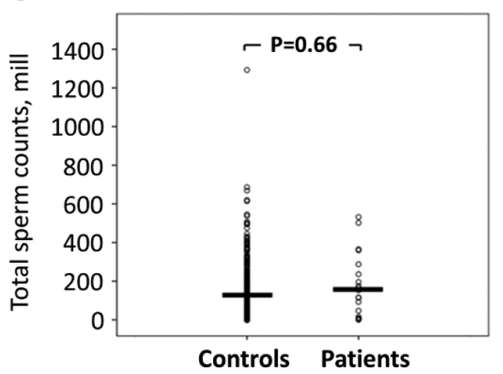

Figure 4

Levels of FSH (A), sperm concentration (B) and total sperm counts (C) in controls and patients. All individual measurements are presented in the figure. Horizontal lines represent the median.

testosterone in all patients, the majority actually had normal semen quality. Therefore, the data suggest that the hypogonadotropic state influences the two components of the gonadal axis, steroidogenesis and spermatogenesis, differently. In support of this hypothesis serum FSH, in contrast to $\mathrm{LH}$, was completely unchanged between patients and controls. Levels of inhibin $b$ were reduced in the patients, but still the majority had serum inhibin $\mathrm{b}$ and FSH-inhibin b combination (bivariate plot) within normal range for proven fertile men.

It is well known, that development of pituitary insufficiency often follows a well-defined pattern with the growth hormone axis as the most frequently affected axis, followed by the gonadal axis, the thyroid axis and the adrenal axis $(5,23)$. As a novel observation, our data point to the possibility that in case of partial pituitary insufficiency spermatogenesis seems more robust than Leydig cell function. In patients with primary gonadal failure, the complete opposite scenario is often observed with severe suppression of spermatogenesis with preserved Leydig cell function (24).

To our knowledge, there are five studies investigating semen quality in patients with hyperprolactinemia naïve to treatment with testosterone or gonadotropins. Serum testosterone at baseline was in all studies comparable to the levels measured in our patients. Semen quality was reported to be reduced, but with very divergent results: In three studies, the sperm concentration at baseline was 6, 19 and 30 million/mL, respectively $(8,9,10)$. The two remaining studies only reported total sperm counts (83 mill (11) and 44 mill, respectively (12). Two small studies ( $n=6$ and $n=7$ ) found very poor semen quality with the majority having azoospermia in patients with acquired, and permanent secondary testosterone deficiency not caused by hyperprolactinemia $(3,25)$. A third study reported data from 10 infertile patients with adult-onset hypogonadotropic hypogonadism requiring gonadotropin treatment. Unfortunately, no specific data on baseline semen quality were provided in the paper, and it is unknown if the patients had been treated with testosterone prior to enrolment (4).

In agreement with the normal sperm counts our patients had testicular volume comparable with the healthy controls. By contrast, two previous studies found low sperm counts despite normal testicular size $(3,4)$. Thus, in patients with adult-onset hypogonadotropic hypogonadism, testicular size may not always be a predictor of semen quality. Compared to controls gynecomastia was more frequently observed in patients, despite reduced levels of estradiol. However, the estradiol/
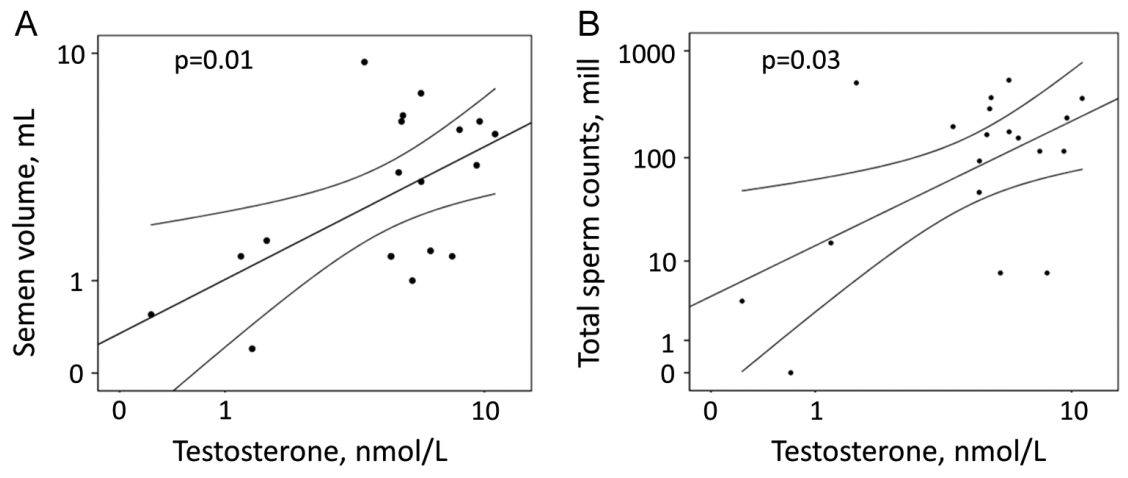

Figure 5

Relationship between testosterone vs semen volume (A) and total sperm counts (B) in patients with secondary hypogonadism.

(c) 2018 The authors
Published by Bioscientifica Ltd

http://www.endocrineconnections.org https://doi.org/10.1530/EC-18-0061

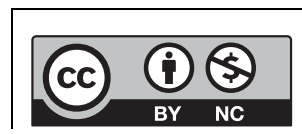

This work is licensed under a Creative Commons Attribution-NonCommercial 4.0 International License. 
testosterone ratio was highly increased in the patients, supporting that it is the balance between androgens and estrogens that are important for development of gynecomastia in hypogonadal men and not the level of estradiol (26).

An important factor that should be considered is the duration of testosterone deficiency. During treatment with supraphysiological doses of testosterone and fully suppressed levels of FSH and LH, oligospermia and in many cases azoospermia, develops after around 3-4 months (27). This is in agreement with the fact that formation of mature sperm takes approximately three months (28). In our study, testosterone deficiency was documented for a median of 3.5 months before evaluation of semen. Moreover, many of our patients already had low testosterone at the initial biochemical evaluation. Thus, the exact duration of low testosterone was unknown, but most likely significantly longer than the documented 3.5 months.

The relative importance of intratesticular testosterone vs FSH stimulation on spermatogenesis in humans is debated. Intratesticular testosterone is believed to play a pivotal role for spermatogenesis and semen volume (1), although data obtained in the so-called fertile eunuch syndrome (congenital testosterone deficiency caused by isolated LH deficiency) show that spermatogenesis can be present despite low testosterone (29). The role of FSH in relation to spermatogenesis is less clear. In experimental models spermatogenesis can be induced by human chorionic gonadotropin (stimulation of LH receptors), in the absence of FSH, but FSH stimulation seems necessary to achieve complete restoration of spermatogenesis $(1,2)$. Thus, a synergic effect between FSH and intratesticular testosterone has been suggested (1). Despite low circulating testosterone in our study, the combined effect of intratesticular testosterone and FSH was sufficient to induce normal spermatogenesis in most patients. However, within the patients both semen volume and total sperm counts were positively associated with testosterone, supporting the importance of intratesticular testosterone.

Taken together, divergent results on semen quality in male patients with secondary testosterone deficiency have been published. We only identified serum testosterone as a predictor of semen quality and volume, whereas for example, underlying disease, levels of gonadotropins or levels of prolactin did not influence semen quality. Based on the available data from the present study duration of testosterone deficiency could also not be identified as a risk factor for poor semen quality. One of twenty patients had azoospermia, and therefore, we will still recommend early cryopreservation of semen in male patients with pituitary disease.

The diagnosis of hypogonadotropic testosterone deficiency was based on repeated measurements of low testosterone, reduced or normal serum concentration of LH and symptoms of testosterone deficiency. Moreover, there were structural changes in the pituitary on magnetic resonance imaging supporting a state of permanent pituitary insufficiency. Serum SHBG was reduced, which per se was unexpected in a testosterone deficient population (30). There could be several explanations including high levels of growth hormone/IGF-I in the acromegalic patients, insufficient replacement therapy with thyroxine and supraphysiological substitution therapy with hydrocortisone. Moreover, it cannot be excluded that higher BMI and higher age in patients compared to controls might have influenced SHBG. We did not have any valid information on tobacco smoking of the patients and can therefore not account for a possible effect on SHBG-levels. However, it should be emphasized that cfT was substantially reduced compared to both the control subjects, and to an age matched reference material.

FSH, LH and thyroid-stimulating hormone (TSH) belong to the glycoprotein hormone family. These hormones consist of a common alfa subunit and a unique beta subunit (31). The hormones are glycosylated, and it has been shown that alterations in glycosylation change the ratio between bioactivity and immunoreactivity (31). This phenomenon has been quite extensively investigated in respect to TSH in patients with central hypothyroidism, and it is now well established that TSH bioactivity is often reduced in patients with pituitary disease $(32,33)$. Analogous to these observations, our data showed reduced testosterone/LH ratio, reduced cfT/LH ratio, and using bivariate plots, we observed an abnormal relationship between total-testosterone and cfT vs the corresponding LH in the majority of patients. Thus, we speculate that the bioactivity of LH might be reduced in male patients with central hypogonadism. This is to our knowledge a new observation. Alternatively, the findings should reflect that patients with pituitary disease in general also had a primary testicular failure, which we consider unlikely. Concerning FSH bioactivity our results are less clear. Reduced inhibin b/FSH ratio in patients point to the possibility of reduced bioactivity. On the other hand, the majority had serum inhibin $b$ and FSH-inhibin b combination (bivariate plot) within normal range for proven fertile men, and they had http://www.endocrineconnections.org https://doi.org/10.1530/EC-18-0061
() 2018 The authors Published by Bioscientifica Ltd
This work is licensed under a Creative Commons Attribution-NonCommercial 4.0 International License. 
normal sperm counts supporting sufficient bioactivity. One previous study has investigated FSH bioactivity in male patients with non-functioning pituitary adenomas and found unchanged in vitro FSH bioactivity. By contrast clinically relevant changes in the bioactivity of gonadotropins have been documented in other clinical conditions such as anorexia nervosa (34), polycystic ovarian disease (35) and primary male hypogonadism (36). Thus, as for TSH, immunoreactive FSH and LH may not reflect FSH and LH bioactivity in patients with pituitary disease, and even a stimulation test probably does not add to the correct diagnosis, since secretion of the dysglycosylated molecules can be stimulated by hypothalamic hormones $(32,37)$. We acknowledge that the hypothesis of reduced bioactivity of gonadotropins is based on speculations and this topic merits further investigations.

There are several limitations to the presented study. The control subjects were not matched for age, but we do not believe that it is a major confounder, since there only seems to be minor changes in semen quality (38) and circulating testosterone levels (39) in individuals aged 20 vs 30 years. We studied a highly selected inhomogeneous group of patients comprising a small non-representative fraction of the entire group of patients diagnosed with hypogonadotropic hypogonadism at our department $(n=409)$. The participants in the study were significantly younger and comprised a large fraction of patients with growth hormone excess, which might per se have a negative influence on semen quality (40). Finally, we did not have data on sperm morphology. There are data suggesting that morphology is affected in patients with secondary hypogonadism due to thalassemia (41).

In conclusion, despite severe testosterone deficiency, 13 of 20 patients had normal semen quality based on the 2010 WHO criteria for total sperm counts and motility. We will recommend, that all patients with secondary testosterone deficiency are offered cryopreservation of semen, before initiation of testosterone therapy. In many cases, cryopreserved semen seems to be of sufficient quality for fertility treatment. With this approach the patient and his partner have the opportunity to decide, if they prefer fertility treatment with cryopreserved semen or testosterone treatment withdrawal, and medical induction of spermatogenesis with gonadotropins, which would be the alternative treatment. Finally, our data point to the possibility that bioactivity of gonadotropins may be reduced in patients with pituitary insufficiency.

http://www.endocrineconnections.org https://doi.org/10.1530/EC-18-0061

C) 2018 The authors Published by Bioscientifica Ltd

\section{Declaration of interest}

The authors declare that there is no conflict of interest that could be perceived as prejudicing the impartiality of the research reported.

\section{Funding}

This research did not receive any specific grant from any funding agency in the public, commercial or not-for-profit sector.

\section{References}

1 Huhtaniemi I. A short evolutionary history of FSH-stimulated spermatogenesis. Hormones 201514 468-478.

2 Matsumoto AM \& Bremner WJ. Endocrinology of the hypothalamicpituitary-testicular axis with particular reference to the hormonal control of spermatogenesis. Bailliere's Clinical Endocrinology and Metabolism 19871 71-87. (https://doi.org/10.1016/S0950351X(87)80053-8)

3 McLachlan RI, Finkel DM, Bremner WJ \& Snyder PJ. Serum inhibin concentrations before and during gonadotropin treatment in men with hypogonadotropic hypogonadism: physiological and clinical implications. Journal of Clinical Endocrinology and Metabolism 199070 1414-1419. (https://doi.org/10.1210/jcem-70-5-1414)

4 Rohayem J, Sinthofen N, Nieschlag E, Kliesch S \& Zitzmann M. Causes of hypogonadotropic hypogonadism predict response to gonadotropin substitution in adults. Andrology 20164 87-94. (https://doi.org/10.1111/andr.12128)

5 Chung TT \& Monson JP. Hypopituitarism. In Endotext. South Dartmouth, MA, USA: MDText.com, Inc., 2000. (available at: https:// www.ncbi.nlm.nih.gov/books/NBK278989/)

6 Boehm U, Bouloux PM, Dattani MT, de RN, Dode C, Dunkel L, Dwyer AA, Giacobini P, Hardelin JP, Juul A, et al. Expert consensus document: European Consensus Statement on congenital hypogonadotropic hypogonadism - pathogenesis, diagnosis and treatment. Nature Reviews Endocrinology 201511 547-564. (https:// doi.org/10.1038/nrendo.2015.112)

7 Mao J, Xu H, Wang X, Huang B, Liu Z, Zhen J, Nie M, Min L \& $\mathrm{Wu} \mathrm{X}$. Congenital combined pituitary hormone deficiency patients have better responses to gonadotrophin-induced spermatogenesis than idiopathic hypogonadotropic hypogonadism patients. Human Reproduction 201530 2031-2037. (https://doi.org/10.1093/humrep/ dev158)

8 De Rosa M, Colao A, Di SA, Ferone D, Landi ML, Zarrilli S, Paesano L, Merola B \& Lombardi G. Cabergoline treatment rapidly improves gonadal function in hyperprolactinemic males: a comparison with bromocriptine. European Journal of Endocrinology 1998138 286-293. (https://doi.org/10.1530/eje.0.1380286)

9 Nishimura K, Matsumiya K, Tsuboniwa N, Yamanaka M, Koga M, Miura H, Tsujimura A, Uchida K, Kondoh N, Kitamura M, et al. Bromocriptine for infertile males with mild hyperprolactinemia: hormonal and spermatogenic effects. Archives of Andrology 199943 207-213. (https://doi.org/10.1080/014850199262517)

10 Colao A, Vitale G, Cappabianca P, Briganti F, Ciccarelli A, De Rosa M, Zarrilli S \& Lombardi G. Outcome of cabergoline treatment in men with prolactinoma: effects of a 24 -month treatment on prolactin levels, tumor mass, recovery of pituitary function, and semen analysis. Journal of Clinical Endocrinology and Metabolism 200489 1704-1711. (https://doi.org/10.1210/jc.2003030979)

11 De Rosa M, Ciccarelli A, Zarrilli S, Guerra E, Gaccione M, Di SA, Lombardi G \& Colao A. The treatment with cabergoline for 24 month normalizes the quality of seminal fluid in

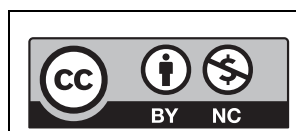

This work is licensed under a Creative Commons Attribution-NonCommercial 4.0 International License. 
hyperprolactinaemic males. Clinical Endocrinology 200664 307-313. (https://doi.org/10.1111/j.1365-2265.2006.02461.x)

12 Walia R, Bhansali A, Dutta P, Khandelwal N, Sialy R \& Bhadada S. Recovery pattern of hypothalamo-pituitary-testicular axis in patients with macroprolactinomas after treatment with cabergoline. Indian Journal of Medical Research 2011134 314-319.

13 Hair WM, Gubbay O, Jabbour HN \& Lincoln GA. Prolactin receptor expression in human testis and accessory tissues: localization and function. Molecular Human Reproduction 20028 606-611. (https://doi. org/10.1093/molehr/8.7.606)

14 Panidis D, Rousso D, Skiadopoulos S, Panidou E \& Mamopoulos M. Evaluation of semen parameters in man with hyperprolactinemia induced by metoclopramide. Archives of Andrology 199739 237-242. (https://doi.org/10.3109/01485019708987922)

15 Ufearo CS \& Orisakwe OE. Restoration of normal sperm characteristics in hypoprolactinemic infertile men treated with metoclopramide and exogenous human prolactin. Clinical Pharmacology and Therapeutics 199558 354-359. (https://doi. org/10.1016/0009-9236(95)90253-8)

16 Bhasin S, Cunningham GR, Hayes FJ, Matsumoto AM, Snyder PJ, Swerdloff RS \& Montori VM. Testosterone therapy in men with androgen deficiency syndromes: an Endocrine Society clinical practice guideline. Journal of Clinical Endocrinology and Metabolism 201095 2536-2559. (https://doi.org/10.1210/jc.2009-2354)

17 Jorgensen N, Joensen UN, Jensen TK, Jensen MB, Almstrup K, Olesen IA, Juul A, Andersson AM, Carlsen E, Petersen JH, et al. Human semen quality in the new millennium: a prospective crosssectional population-based study of 4867 men. BMJ Open 20122 e000990.

18 Cooper TG, Noonan E, von ES, Auger J, Baker HW, Behre HM, Haugen TB, Kruger T, Wang C, Mbizvo MT, et al. World Health Organization reference values for human semen characteristics. Human Reproduction Update 201016 231-245. (https://doi. org/10.1093/humupd/dmp048)

19 Vermeulen A, Verdonck L \& Kaufman JM. A critical evaluation of simple methods for the estimation of free testosterone in serum. Journal of Clinical Endocrinology and Metabolism 199984 3666-3672. (https://doi.org/10.1210/jcem.84.10.6079)

20 Petersen JH. Two bivariate geometrically defined reference regions with applications to male reproductive hormones and human growth. Statistics in Medicine 200322 2603-2618. (https://doi. org/10.1002/sim.1480)

21 Aksglaede L, Andersson AM, Jorgensen N, Jensen TK, Carlsen E, McLachlan RI, Skakkebaek NE, Petersen JH \& Juul A. Primary testicular failure in Klinefelter's syndrome: the use of bivariate luteinizing hormone-testosterone reference charts. Clinical Endocrinology 200766 276-281. (https://doi.org/10.1111/j.13652265.2006.02722.x)

22 Andersson AM, Petersen JH, Jorgensen N, Jensen TK \& Skakkebaek NE. Serum inhibin B and follicle-stimulating hormone levels as tools in the evaluation of infertile men: significance of adequate reference values from proven fertile men. Journal of Clinical Endocrinology and Metabolism 200489 2873-2879. (https://doi. org/10.1210/jc.2003-032148)

23 Feldt-Rasmussen U \& Klose M. Central hypothyroidism and its role for cardiovascular risk factors in hypopituitary patients. Endocrine 201654 15-23. (https://doi.org/10.1007/s12020-016-1047-x)

24 Jorgensen N, Joensen UN, Toppari J, Punab M, Erenpreiss J, Zilaitiene B, Paasch U, Salzbrunn A, Fernandez MF, Virtanen HE, et al. Compensated reduction in Leydig cell function is associated with lower semen quality variables: a study of 8182 European young men. Human Reproduction 201631 947-957. (https://doi.org/10.1093/ humrep/dew021)

25 Finkel DM, Phillips JL \& Snyder PJ. Stimulation of spermatogenesis by gonadotropins in men with hypogonadotropic hypogonadism. http://www.endocrineconnections.org https://doi.org/10.1530/EC-18-0061 (c) 2018 The authors Published by Bioscientifica Ltd
New England Journal of Medicine 1985313 651-655. (https://doi.

26 Mieritz MG, Christiansen P, Jensen MB, Joensen UN, Nordkap L, Olesen IA, Bang AK, Juul A \& Jorgensen N. Gynaecomastia in 786 adult men: clinical and biochemical findings. European Journal of Endocrinology 2017176 555-566. (https://doi.org/10.1530/EJE-160643)

27 Crosnoe LE, Grober E, Ohl D \& Kim ED. Exogenous testosterone: a preventable cause of male infertility. Translational Andrology and Urology 20132 106-113.

28 Heller CG \& Clermont Y. Spermatogenesis in man: an estimate of its duration. Science 1963140 184-186. (https://doi.org/10.1126/ science.140.3563.184)

29 Rogol AD, Mittal KK, White BJ, McGinniss MH, Lieblich JM \& Rosen SW. HLA-compatible paternity in two 'fertile eunuchs' with congenital hypogonadotropic hypogonadism and anosmia (the Kallmann syndrome). Journal of Clinical Endocrinology and Metabolism 198051 275-279. (https://doi.org/10.1210/jcem-51-2-275)

30 Pugeat M, Crave JC, Tourniaire J \& Forest MG. Clinical utility of sex hormone-binding globulin measurement. Hormone Research 199645 148-155. (https://doi.org/10.1159/000184778)

31 Bousfield GR \& Dias JA. Synthesis and secretion of gonadotropins including structure-function correlates. Reviews in Endocrine and Metabolic Disorders 201112 289-302. (https://doi.org/10.1007/ s11154-011-9191-3)

32 Horimoto M, Nishikawa M, Ishihara T, Yoshikawa N, Yoshimura M \& Inada M. Bioactivity of thyrotropin (TSH) in patients with central hypothyroidism: comparison between in vivo 3,5,3'-triiodothyronine response to TSH and in vitro bioactivity of TSH. Journal of Clinical Endocrinology and Metabolism 199580 1124-1128.

33 Beck-Peccoz P, Amr S, Menezes-Ferreira MM, Faglia G \& Weintraub BD. Decreased receptor binding of biologically inactive thyrotropin in central hypothyroidism. Effect of treatment with thyrotropin-releasing hormone. New England Journal of Medicine 1985312 1085-1090. (https://doi.org/10.1056/ NEJM198504253121703)

34 Tommaselli AP, Valentino R, Savastano S, Randazzo G, Scalfi L, Contaldo F, Dorato M \& Lombardi G. Altered glycosylation of pituitary gonadotropins in anorexia nervosa: an alternative explanation for amenorrhea. European Journal of Endocrinology 1995 132 450-455. (https://doi.org/10.1530/eje.0.1320450)

35 Fauser BC, Pache TD, Lamberts SW, Hop WC, de Jong FH \& Dahl KD. Serum bioactive and immunoreactive luteinizing hormone and follicle-stimulating hormone levels in women with cycle abnormalities, with or without polycystic ovarian disease. Journal of Clinical Endocrinology and Metabolism 199173 811-817. (https://doi. org/10.1210/jcem-73-4-811)

36 Carani C, Celani MF, Zini D, Baldini A, Della CL \& Marrama P. Changes in the bioactivity to immunoreactivity ratio of circulating luteinizing hormone in impotent men treated with testosterone undecanoate. Acta Endocrinologica 1989120 284-288. (https://doi. org/10.1530/acta.0.1200284)

37 Hartoft-Nielsen ML, Lange M, Rasmussen AK, Scherer S, Zimmermann-Belsing T \& Feldt-Rasmussen U. Thyrotropin-releasing hormone stimulation test in patients with pituitary pathology. Hormone Research 200461 53-57.

38 Perheentupa A, Sadov S, Ronka R, Virtanen HE, Rodprasert W, Vierula M, Jorgensen N, Skakkebaek NE \& Toppari J. Semen quality improves marginally during young adulthood: a longitudinal follow-up study. Human Reproduction 201631 502-510. (https://doi. org/10.1093/humrep/dev328)

39 Travison TG, Vesper HW, Orwoll E, Wu F, Kaufman JM, Wang Y, Lapauw B, Fiers T, Matsumoto AM \& Bhasin S. Harmonized reference ranges for circulating testosterone levels in men of four cohort studies in the United States and Europe. Journal of Clinical org/10.1056/NEJM198509123131102)

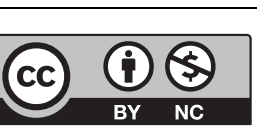

This work is licensed under a Creative Commons Attribution-NonCommercial 4.0 International License. 
Endocrinology and Metabolism 2017102 1161-1173. (https://doi. org/10.1210/jc.2016-2935)

40 Colao A, De Rosa M, Pivonello R, Balestrieri A, Cappabianca P, Di SA, Rochira V, Carani C \& Lombardi G. Short-term suppression of GH and IGF-I levels improves gonadal function and sperm parameters in men with acromegaly. Journal of Clinical Endocrinology and
Metabolism 200287 4193-4197. (https://doi.org/10.1210/jc.2002020453)

41 Safarinejad MR. Evaluation of semen quality, endocrine profile and hypothalamus-pituitary-testis axis in male patients with homozygous beta-thalassemia major. Journal of Urology 2008179 2327-2332. (https://doi.org/10.1016/j.juro.2008.01.103)

Received in final form 2 March 2018

Accepted 7 March 2018

Accepted Preprint published online 7 March 2018 http://www.endocrineconnections.org https://doi.org/10.1530/EC-18-0061
() 2018 The authors Published by Bioscientifica Ltd

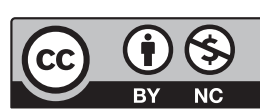

This work is licensed under a Creative Commons Attribution-NonCommercial 4.0 International License. 